\title{
QUALIDADE DA ÁGUA RESIDUÁRIA PARA IRRIGAÇÃO DO TRIGO
}

\author{
ANA CAROLINA BARBOSA KUMMER ${ }^{1}$; ILCA PUERTAS DE FREITAS E \\ SILVA $^{2}$; THOMAZ FIGUEIREDO LOBO ${ }^{3}$; HÉLIO GRASSI FILHO ${ }^{4}$ \\ ${ }^{1}$ Eng. Agrícola, Mestre em Eng. Agrícola - Recursos Hídricos e Saneamento Ambiental, Doutoranda em \\ Agronomia - Irrigação e Drenagem, UNESP/FCA, Botucatu-SP. E-mail: anak_doc@yahoo.com.br \\ ${ }^{2}$ Eng Agrônoma, Mestranda em Agronomia - Agricultura, UNESP/FCA, Botucatu-SP, E-mail: \\ ilca_pfs@yahoo.com.br \\ ${ }^{3}$ Eng. Agrônomo, Mestre e Doutor em Agronomia, Pós-Doutorando em Agronomia, UNESP/FCA, Botucatu-SP. \\ E-mail: thomaz.lobo@superig.com.br \\ ${ }^{4}$ Prof. Adjunto Departamento de Recursos Naturais e Ciência do Solo, UNESP/FCA, Botucatu-SP. E-mail: \\ heliograssi@fca.unesp.br
}

\section{RESUMO}

O tratamento de esgotos sanitários e o seu posterior reúso, tornou-se uma alternativa viável para a irrigação, atividade que utiliza em torno de $70 \%$ de toda a água consumida no planeta. Nesse sentido, o objetivo deste estudo foi monitorar durante todo o ciclo do trigo, os teores de Ferro e Manganês, bem como valores de $\mathrm{pH}$ e condutividade elétrica da água residuária utilizada para irrigação da cultura por gotejamento. A água residuária utilizada no estudo foi proveniente da Estação de Tratamento de Esgotos (ETE) da cidade de Botucatu-SP. No período de maio a outubro de 2011 a amostragem da água residuária foi realizada semanalmente, na saída da ETE. Foram determinados os seguintes parâmetros: Boro (B), Cobre $(\mathrm{Cu})$, Ferro $(\mathrm{Fe})$, Manganês $(\mathrm{Mn})$ e Zinco $(\mathrm{Zn})$, segundo metodologia adaptada de Malavolta et al. (1997). O pH e a condutividade elétrica (CE) foram determinados com auxilio de um pHmetro e condutivímetro, respectivamente. Não foi observado teores de $\mathrm{Fe} e$ Mn e valores de $\mathrm{pH}$ que comprometessem o sistema de irrigação, ou seja, que apresentasse alto potencial de risco de obstrução de tubulações e emissores (gotejamento). Os valores de $\mathrm{CE}$ indicam que a água residuária pode ser usada no solo, sempre que houver grau elevado de lixiviação, sem maior comprometimento das culturas.

Palavras-Chave: reúso; gotejamento; micronutrientes

\section{KUMMER, A. C. B.; de FREITAS e SILVA, I. P.; LOBO, T. F.; GRASSI FILHO, H. QUALITY OF WASTEWATER FOR WHEAT IRRIGATION}

\section{ABSTRACT}

The treatment of sewage and its reuse, became a viable alternative for irrigation, an activity that uses approximately $70 \%$ of all water consumed on the planet. The objective of this study was to monitor during stages of wheat, the levels of iron and manganese, as well as $\mathrm{pH}$ and conductivity of the wastewater used for irrigation drip of culture. The wastewater used in the study came from the Sewage Treatment Plant (WWTP) in the city of Botucatu-SP. In the period from May to October 2011 sampling of the wastewater was carried out weekly at the outlet of the WWTP. Parameters were determined: boron $(\mathrm{B})$, copper $(\mathrm{Cu})$, iron $(\mathrm{Fe})$, manganese (Mn) and zinc ( $\mathrm{Zn})$, using methods adapted from Malavolta et al. (1997). The $\mathrm{pH}$ 
and electrical conductivity (EC) were determined with $\mathrm{pH}$-meter and conductivity-meter, respectively. There was no $\mathrm{Fe}$ and $\mathrm{Mn}$ and $\mathrm{pH}$ values that could compromise the irrigation system, in other words, to present high potential risk of clogging of pipes and emitters (drip). The EC values indicate that the wastewater can be used in the soil, where there is high degree of leaching without further involvement of the cultures.

Keywords: reuse; drip irrigation; micronutrient

\section{INTRODUÇÃO}

Nas últimas décadas o aumento da população e o crescimento industrial intensificaram os efeitos negativos decorrentes das atividades humanas, principalmente no que se refere aos usos múltiplos da água. As retiradas permanentes para diversas finalidades têm diminuído consideravelmente a disponibilidade de água, produzindo inúmeros problemas de escassez em muitas regiões e países. Assim, o tratamento de esgotos sanitários e o seu posterior reúso, tornou-se uma alternativa viável para a irrigação, atividade que utiliza em torno de $70 \%$ de toda a água consumida no planeta.

No Brasil, o reúso de água encontra uma gama significativa de aplicações potenciais. $\mathrm{O}$ uso de efluentes tratados na agricultura, nas áreas urbanas, particularmente para fins não potáveis, no atendimento da demanda industrial e na recarga artificial de aquíferos, se constitui em instrumento poderoso para restaurar o equilíbrio entre oferta e demanda de água em diversas regiões brasileiras.

A utilização de efluentes na agricultura cresceu consideravelmente nos últimos anos em muitos países, inclusive no Brasil; no entanto, ainda não foram suficientemente estudados todos os aspectos positivos e negativos dessa técnica, especialmente sobre as propriedades físicas e químicas do solo, absorção de nutrientes pelas plantas ou sua toxidez (Sandri et al., 2006).

A falta de informações sobre a qualidade da água a ser utilizada na agricultura pode propiciar efeitos negativos nas propriedades físico-químicas do solo e no rendimento das culturas (Moraes, 1998), assim como no sistema de irrigação.

Para Smanhotto (2008) o reúso de água na agricultura é como instrumento adicional para a gestão dos recursos hídricos, visando ao controle da poluição de corpos d'água, disponibilização de água e fertilizantes para as culturas, reciclagem de nutrientes e aumento de produção agrícola.

Caovilla et al. (2005) lembram que um dos principais fatores que justifica o uso de águas residuárias na agricultura refere-se à possibilidade de reduzir o uso de fertilizantes químicos. Estudos reportam que a economia no custo de produção pode atingir até $50 \%$ com o uso desta técnica. Outros fatores, porém, também merecem destaque, como: disponibilidade mais frequente de água, melhoria na qualidade dos solos e consequente aumento do rendimento dos cultivos, permitindo em alguns casos, a ampliação da fronteira agrícola.

Muitas pesquisas têm demonstrado que a produção agrícola é maior quando alguma forma de água residuária é usada em comparação com água de abastecimento com adição de fertilizantes artificiais. Vários autores mencionam a possibilidade de substituição parcial de fertilizantes químicos, com a diminuição do impacto ambiental, em função da redução da contaminação dos cursos d'água; um significativo aumento na produção, tanto qualitativo quanto quantitativo; além da economia da quantidade de água direcionada para a irrigação. 
Segundo Brega Filho e Mancuso (2002), a prática de reúso de água no meio agrícola, pode garantir a recarga do lençol freático, garantir a dessedentação de animais além de servir para fertirrigação de diversas culturas. Vale lembrar que a água proveniente do reuso é diferenciada para a irrigação de plantas não comestíveis (silvicultura, pastagens, fibras e sementes) e comestíveis (nas formas cruas e cozidas), necessitando essas de um nível maior de qualidade.

O uso de águas residuárias, não é um conceito novo e tem sido praticado em todo mundo há muitos anos. No entanto, a demanda crescente por água tem feito do reúso planejado da água um tema atual e de grande importância. Neste sentido, deve-se considerar o reúso de água como parte de uma atividade mais abrangente que é o uso racional ou eficiente da água, o qual compreende também o controle de perdas e desperdícios, e a minimização da produção de efluentes e do consumo de água (Almeida, 2010).

Associado a esse conceito tem-se a pratica da agricultura irrigada, que é parte de um conjunto de técnicas utilizadas para garantir a produção econômica de determinada cultura com adequados manejos dos recursos naturais.

Dessa maneira, quando se procura usar um sistema de irrigação localizado, a qualidade da água é de extrema importância, tanto na vida útil do sistema, como na uniformidade da distribuição da água de irrigação. No entanto, vários fatores podem comprometer esta uniformidade. $\mathrm{O}$ entupimento de emissores/gotejadores pode resultar de causas físicas, biológicas ou químicas. O bom desempenho desses sistemas deve ser maximizado a fim de assegurar uma relação custo/benefício favorável. Portanto, se os emissores/gotejadores entopem em um curto espaço de tempo, os procedimentos de recuperação adicionarão custos para a manutenção do sistema, levando à queda de produtividade e qualidade dos produtos (Silva et al. 2012).

Nesse sentido, o objetivo deste estudo foi monitorar durante todo o ciclo do trigo, os teores de Ferro e Manganês, bem como valores de $\mathrm{pH}$ e condutividade elétrica da água residuária utilizada para irrigação da cultura por gotejamento, e confrontar os dados obtidos com dados da literatura, principalmente no que se refere ao potencial de entupimento dos gotejadores, quando na presença de determinados elementos.

\section{MATERIAL E MÉTODOS}

O estudo foi conduzido no Departamento de Recursos Naturais e Ciência do Solo da Faculdade de Ciências Agronômicas, Universidade Estadual Paulista "Júlio de Mesquita Filho", Botucatu-SP.

A altitude média da região varia entre 400 e 900 m e o clima é subtropical úmido, de acordo com a classificação climática de Köppen. A precipitação média anual é de $1400 \mathrm{~mm}$ e a temperatura média anual é de $20^{\circ} \mathrm{C}$.

No período de maio a outubro de 2011 foi realizado o monitoramento, em termos de micronutrientes, $\mathrm{pH}$ e condutividade elétrica, da água residuária utilizada para irrigação localizada na cultura do trigo em ambiente protegido.

O trigo, variedade CD150, foi cultivado em 70 vasos com capacidade de $42,5 \mathrm{~L}$ os quais foram mantidos em casa de vegetação não climatizada (estufa plástica), modelo arco, com pé-direito aproximado de $2 \mathrm{~m}$, largura de $5 \mathrm{~m}$ e comprimento de $20 \mathrm{~m}$.

A irrigação da cultura se deu através do método do Tanque Classe $\mathrm{A}$, atendendo a necessidade hídrica da cultura, durante todo o ciclo. 
Adotou-se o sistema de irrigação localizada por gotejamento, onde os gotejadores utilizados eram autocompensantes com vazão de $4 \mathrm{~L} \mathrm{~h}^{-1}$.

O sistema de irrigação consistiu em 1 linha de derivação e 3 linhas laterais com 23 gotejadores cada uma, com exceção da última linha que possuía 24 gotejadores, além do conjunto motobomba de $1 / 3 \mathrm{CV}$, filtro de discos autolimpante, e um manômetro para controle da pressão do sistema.

A água residuária foi proveniente da Estação de Tratamento de Esgotos - ETE do município de Botucatu-SP. A cada semana a água era transportada, com caminhão pipa, da ETE até o local de estudo e depositada em reservatório fechado com capacidade para 1000L (Figura 1).

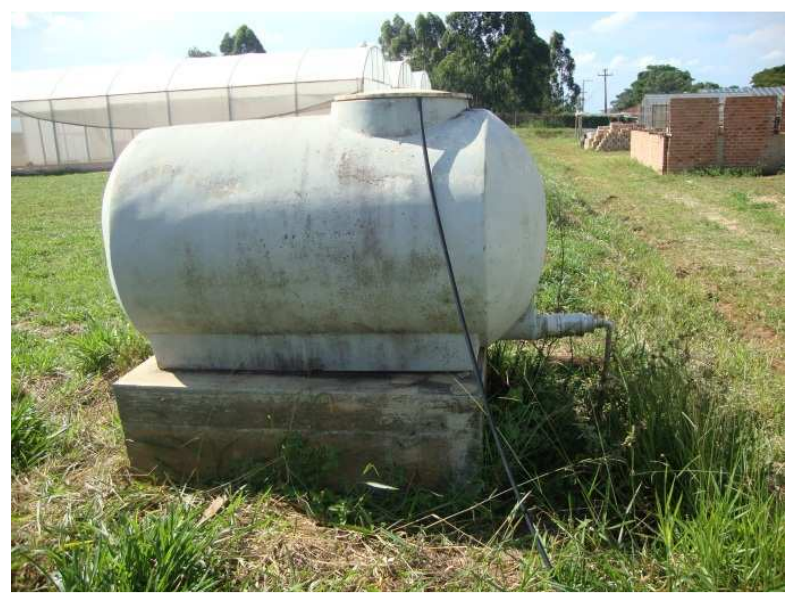

Figura 1. Reservatório de água residuária

A amostragem da água residuária foi realizada semanalmente, no momento da coleta, ou seja, na saída da ETE, em frascos plásticos transparentes, os quais eram preservados à temperatura de 0 a $4^{\circ} \mathrm{C}$ até o momento da análise. Foram determinados os seguintes parâmetros: Boro (B), Cobre $(\mathrm{Cu})$, Ferro $(\mathrm{Fe})$, Manganês $(\mathrm{Mn})$ e Zinco $(\mathrm{Zn})$, segundo metodologia adaptada de Malavolta et al. (1997). O pH e a condutividade elétrica (CE) foram determinados com auxilio de um pHmetro e condutivímetro, respectivamente.

\section{RESULTADOS E DISCUSSÃO}

Quando se fala em reúso para irrigação agrícola, deve-se estar atentos a certos componentes presentes na água residuária, os quais podem ter efeitos benéficos ou não, às plantas. Assim, na Tabela 1 são apresentados os valores de Boro (B), Cobre $(\mathrm{Cu})$, Ferro $(\mathrm{Fe})$, Manganês (Mn) e Zinco ( $\mathrm{Zn})$, Condutividade Elétrica (CE) e pH observados na água residuária utilizada do estudo, bem como o período de amostragem. 
Tabela 1. Teores de micronutrientes e valores de condutividade elétrica e $\mathrm{pH}$ na água residuária

\begin{tabular}{cccccccc}
\hline Data & B & $\mathrm{Cu}$ & $\mathrm{Fe}$ & $\mathrm{Mn}$ & $\mathrm{Zn}$ & $\mathrm{CE}$ & $\mathrm{pH}$ \\
& -------------------- & $\mathrm{mg} / \mathrm{L}---------------------$ & $\mathrm{dS} / \mathrm{m}$ & \\
\hline $04 / 05 / 2011$ & 0,53 & 0,00 & 0,13 & 0,00 & 0,03 & 0,63 & 7,02 \\
$10 / 05 / 2011$ & 0,46 & 0,00 & 0,21 & 0,00 & 0,01 & 0,65 & 7,20 \\
$16 / 05 / 2011$ & 0,35 & 0,00 & 0,27 & 0,00 & 0,01 & 0,59 & 7,24 \\
$23 / 05 / 2011$ & 0,36 & 0,00 & 0,41 & 0,00 & 0,01 & 0,71 & 7,64 \\
$30 / 05 / 2011$ & 0,00 & 0,00 & 5,30 & 0,61 & 0,11 & 0,62 & 6,88 \\
\hline $06 / 06 / 2011$ & 0,00 & 0,00 & 2,15 & 0,21 & 0,05 & 0,59 & 7,22 \\
$15 / 06 / 2011$ & 0,00 & 0,00 & 0,52 & 0,11 & 0,05 & 0,63 & 7,12 \\
$27 / 06 / 2011$ & 0,00 & 0,00 & 0,41 & 0,11 & 0,04 & 0,61 & 7,44 \\
\hline $06 / 07 / 2011$ & 0,39 & 0,00 & 0,08 & 0,05 & 0,02 & 0,60 & 6,51 \\
$20 / 07 / 2011$ & 0,22 & 0,00 & 0,12 & 0,01 & 0,01 & 0,68 & 7,24 \\
$29 / 07 / 2011$ & 0,35 & 0,00 & 0,11 & 0,00 & 0,01 & 0,70 & 6,99 \\
\hline $02 / 08 / 2011$ & 0,57 & 0,00 & 0,09 & 0,02 & 0,01 & 0,69 & 7,19 \\
$08 / 08 / 2011$ & 0,46 & 0,00 & 0,13 & 0,02 & 0,00 & 0,58 & 6,63 \\
$15 / 08 / 2011$ & - & 0,00 & 0,00 & 0,00 & 0,00 & 0,55 & 7,08 \\
$22 / 08 / 2011$ & - & 0,00 & 0,00 & 0,00 & 0,00 & 0,56 & 7,28 \\
$29 / 08 / 2011$ & - & 0,00 & 0,36 & 0,02 & 0,00 & 0,56 & 7,48 \\
\hline $05 / 09 / 2011$ & - & 0,00 & 0,18 & 0,04 & 0,00 & 0,59 & 7,60 \\
$13 / 09 / 2011$ & - & 0,02 & 0,29 & 0,06 & 0,00 & 0,70 & 7,19 \\
$19 / 09 / 2011$ & - & 0,02 & 0,27 & 0,06 & 0,00 & 0,79 & 7,35 \\
$26 / 09 / 2011$ & - & 0,02 & 0,25 & 0,04 & 0,00 & 0,67 & 7,12 \\
\hline $03 / 10 / 2011$ & - & 0,01 & 0,93 & 0,05 & 0,00 & 0,71 & 6,20 \\
$23 / 10 / 2011$ & - & 0,00 & 0,15 & 0,00 & 0,00 & 0,60 & 7,81 \\
$26 / 10 / 2011$ & - & 0,00 & 0,62 & 0,00 & 0,00 & 0,51 & 7,75 \\
\hline
\end{tabular}

Vale lembrar que dependendo do componente encontrado na água, este pode vir a comprometer de maneira negativa o sistema de irrigação, implicando em perdas de produtividade.

Dentre os componentes encontrados em águas residuárias podem-se citar os nutrientes, os quais são variáveis em função do tipo de esgoto, da parcela de contribuição: industrial ou estritamente doméstica, além do processo de tratamento empregado no tratamento dessa água.

Para este estudo a água residuária foi proveniente da ETE que recebe e trata esgoto doméstico, sem relatos de coleta e tratamento de efluentes industriais.

Durante todo o período de monitoramento (Tabela 1) foram observados teores de micronutrientes em maior ou menor quantidade dependendo da época de amostragem, com exceção do boro, cujas análises se deram somente até meados do mês de agosto.

Se considerarmos as médias mensais (Figuras 2 e 3) nota-se que o cobre e zinco apresentaram comportamento inverso, ou seja, teores de zinco foram detectados até o mês de agosto, enquanto que para o cobre os teores apareceram a partir de setembro. 
$\mathrm{Cu}$

( $\left.\mathrm{mg} \mathrm{L}^{-1}\right)$

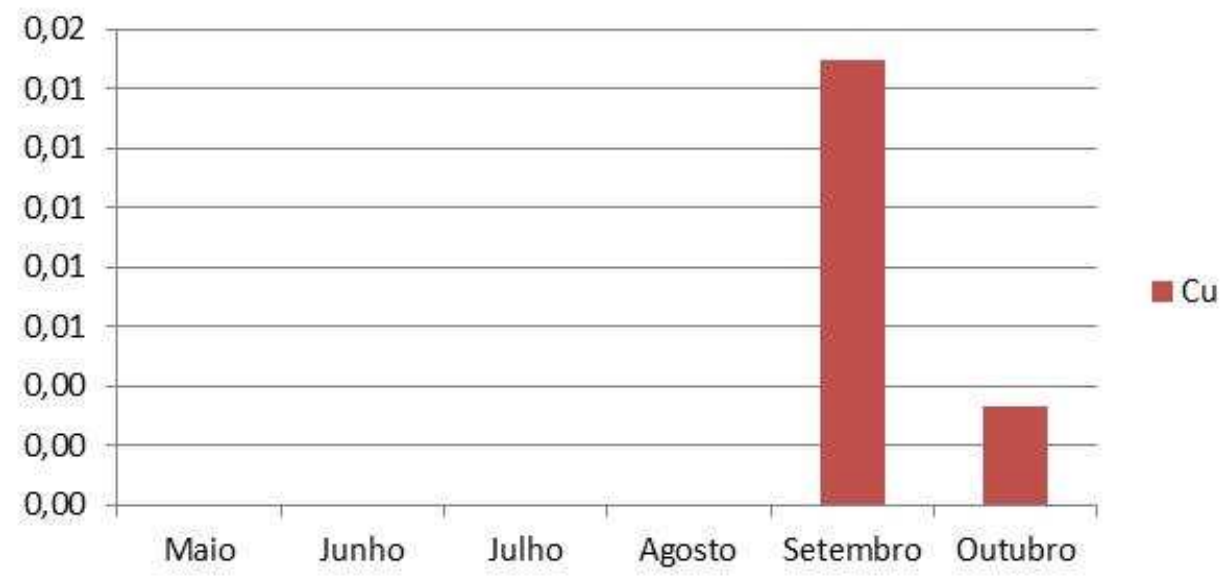

Figura 2. Valores médios mensais de Cobre.

$\mathrm{Zn}$

$\left(\mathrm{mg} \mathrm{L}^{-1}\right)$

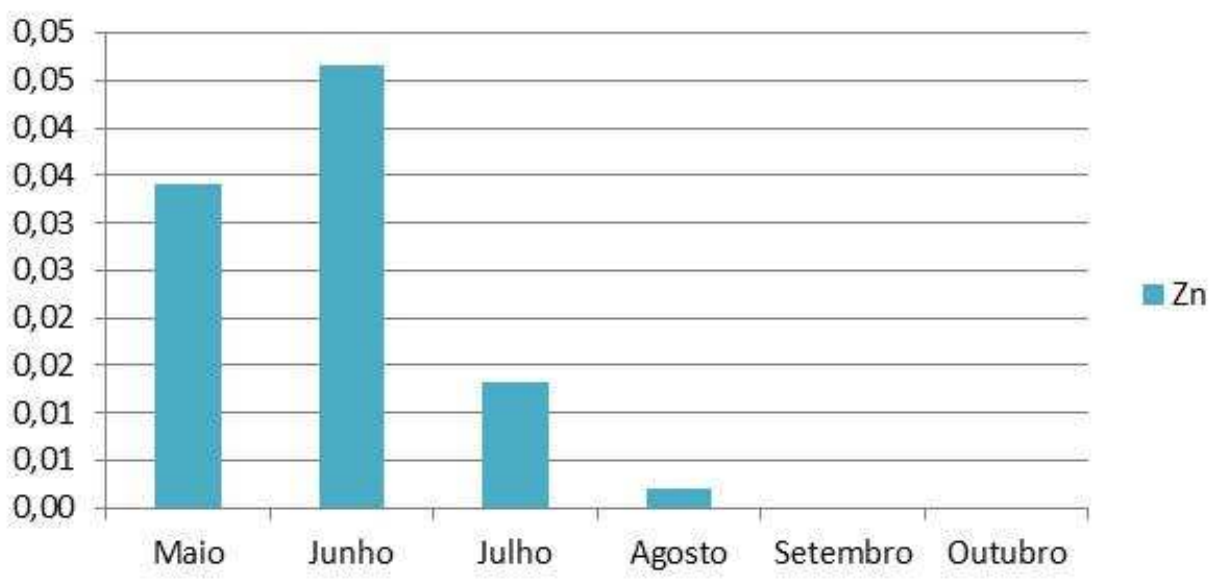

Figura 3. Valores médios mensais de Zinco.

Blum (2003) relata que as águas residuárias provenientes dos esgotos municipais geralmente contêm nutrientes necessários para o crescimento e desenvolvimento das plantas. Nesse sentido, vale mencionar que os nutrientes de grande interesse além do Nitrogênio, Fósforo e Potássio, são o Zinco e o Boro, cujos teores nessas águas geralmente atendem, se não toda, pelo menos boa parte das necessidades das plantas em geral.

Segundo Kirkham (1986) a alta concentração de boro pode ser encontrada em efluente doméstico, normalmente entre 0,5 e $1,0 \mathrm{mg} \mathrm{L}^{-1}$, sendo atribuído ao uso de componentes à base de boro, em produtos de limpeza. Em geral a concentração de boro no período estudado não ultrapassou $0,5 \mathrm{mg} \mathrm{L}^{-1}$, exceto na primeira semana de maio e de agosto, permanecendo, no entanto, na faixa compreendida entre 0,5 e $1,0 \mathrm{mg} \mathrm{L}^{-1}$. Para Brasil (2005) o limite máximo de boro na água de irrigação da Classe 1 , é de $0,5 \mathrm{mg} \mathrm{L}^{-1}$. Já para Trani (2001) os valores limite estão entre 0,5 e $1,0 \mathrm{mg} \mathrm{L}^{-1}$. 
$\mathrm{Na}$ Tabela 2 são apresentados para constituintes em águas de reuso para irrigação agrícola.

Tabela 2. Limites recomendados para águas de irrigação agrícola**.

\section{Limite Recomendado}

Constituinte

\begin{tabular}{|c|c|c|c|}
\hline & & & \\
\hline & Limite LP* & Limite $\mathrm{CP}^{*}$ & \\
\hline Boro & 0,75 & 2,0 & 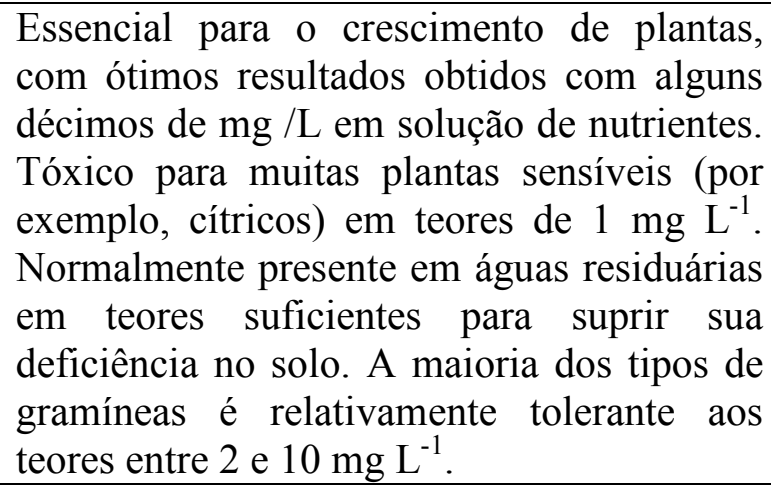 \\
\hline Cobre & 0,2 & 5,0 & $\begin{array}{l}\text { Tóxico para vários tipos de plantas em } \\
\text { teores entre } 0,1 \text { e } 1,0 \mathrm{mg} \mathrm{L}^{-1} \text { em solução de } \\
\text { nutrientes. }\end{array}$ \\
\hline Ferro & 5,0 & 20,0 & $\begin{array}{l}\text { Não tóxico para as plantas em solos aerados, } \\
\text { mas pode contribuir para acidificação e } \\
\text { perda de fósforo e molibdênio. }\end{array}$ \\
\hline Manganês & 0,2 & 10,0 & $\begin{array}{l}\text { Tóxico para vários tipos de plantas em } \\
\text { teores entre alguns décimos até algumas } \\
\text { unidades de } \mathrm{mg} \mathrm{L}^{-1} \mathrm{em} \mathrm{solos} \mathrm{ácidos.}^{-}\end{array}$ \\
\hline Zinco & 2,0 & 10,0 & $\begin{array}{l}\text { Tóxico a várias plantas em concentrações } \\
\text { bastante variadas: a toxicidade é reduzida } \\
\text { em pH mais alto ( } 6 \text { ou mais) e em solos } \\
\text { orgânicos ou de textura fina. }\end{array}$ \\
\hline
\end{tabular}

Significado

*LP - Limites para uso da água por longos períodos; CP - Idem, por curtos períodos.

**Adaptado de Usepa (1999) e Crook (1993) citados por Blum (2003).

Comparando-se os resultados obtidos na Tabela 1 com as informações da Tabela 2, observa-se que os teores de: boro, cobre e zinco não ultrapassaram os valores limites recomendado para uso da água por longos períodos. Quanto ao ferro e manganês, na última semana de maio, apresentaram teores superiores ao limite recomentado. Entretanto a média mensal (Figuras 3 e 4) do teor desses elementos não ultrapassou o limite recomentado. 
$\mathrm{Fe}$

(mg L $\left.\mathrm{L}^{-1}\right)$



Figura 4. Valores médios mensais de Ferro.



Figura 5. Valores médios mensais de Manganês.

$\mathrm{Na}$ Tabela 3 é apresentada a classificação da qualidade da água em relação ao potencial de entupimento dos gotejadores**.

Tabela 3. Risco de entupimento de gotejadores em função dos parâmetros químicos Fe, Mn, sólidos dissolvidos e $\mathrm{pH}$.

Fator de entupimento
Risco de entupimento

\begin{tabular}{cccc} 
& Baixo & Moderado & Severo \\
\cline { 2 - 4 } & $<0,2$ & $0,2-1,5$ & $>1,5$ \\
Ferro $^{*}$ mg L $\left.^{-1}\right)$ & $<0,1$ & $0,1-1,0$ & $>1,0$ \\
$\begin{array}{c}\text { Manganês } \\
\left(\text { mg L }^{-1}\right)\end{array}$ & $<500$ & $500-2000$ & $>2000$ \\
$\begin{array}{c}\text { Sólidos } \\
\text { Dissolvidos }\end{array}$ & $<7,0$ & $7,0-8,0$ & $>8,0$ \\
pH & & & \\
\hline
\end{tabular}


*Concentração máxima medida com um número representativo e amostras de água usando-se procedimentos-padrão para análise;

**Adaptado de Gilbert e Ford (1986) citados por Mantovani et al. (2009).

$\mathrm{Na}$ água residuária, a concentração de ferro não ultrapassou $1,0 \mathrm{mg} \mathrm{L}^{-1}$, exceto na última semana de maio e primeira semana de junho, cujos valores foram de 5,30 e $2,15 \mathrm{mg} \mathrm{L}^{-1}$, respectivamente. Mas em geral esses valores estão de acordo com Trani e Carrijo (2004) que relataram que os valores máximos de ferro na água de irrigação devem estar entre 0,2 e $1,5 \mathrm{mg} \mathrm{L}^{-1}$ pois acima do limite superior, pode ocorrer precipitação de $\mathrm{F}_{2} \mathrm{Cl}_{3}$ em águas com altos teores de cloro.

Segundo Hernandez et al. (2001), o ferro atualmente é um dos principais problemas na água de irrigação, devido a sua capacidade de obstruir fisicamente as tubulações e emissores dos sistemas localizados. Isto ocorre porque o ferro reduzido $\left(\mathrm{Fe}^{2+}\right)$ é solúvel e, ao atravessar o sistema de filtragem, pode se oxidar, tornando-se insolúvel $\left(\mathrm{Fe}^{3+}\right)$. Após a oxidação, ferro fica retido nas paredes do tubo, provocando o aumento nas perdas de carga, comprometendo o projeto de irrigação.

Embora os teores de ferro (Figura 4) tenham sido mais elevados nos meses de maio e junho de 2011, observa-se que nenhum deles ultrapassou $1,5 \mathrm{mg} \mathrm{L}^{-1}$, indicando que a água residuária proveniente de ETE utilizada neste estudo oferece risco moderado de entupimento para esses meses (Tabela 3). Os valores elevados no teor de ferro para os meses de maio e junho podem estar associados ao período de estiagem para a região de Botucatu-SP, implicando num aumento na concentração de certos elementos presentes na água, visto que não há diluição pela água da chuva. A partir de julho os valores caíram drasticamente não ultrapassando $0,2 \mathrm{mg} \mathrm{L}^{-1}$ com exceção do mês de outubro onde a água residuária apresentou teor médio mensal de Fe de $0,57 \mathrm{mg} \mathrm{L}^{-1}$ (Figura 4).

Segundo critérios observados na Figura 5 e Tabela 3, verifica-se que a maior parte dos teores de manganês não ultrapassaram $0,1 \mathrm{mg} \mathrm{L}^{-1}$, com exceção dos meses de maio e junho que apresentaram valores de 0,12 e $0,14 \mathrm{mg} \mathrm{L}^{-1}$, respectivamente, indicando risco moderado de entupimento.

Vale lembrar que o risco de entupimento em sistemas de irrigação por gotejamento pode ocorrer por diversas causas, dentre elas: presença de sólidos suspensos, presença de areia e silte, fitoplancton, uso de fertilizantes que aumentam a alcalinidade da água (precipitação de substancias químicas) e ação de bactérias que podem oxidar ferro, manganês e enxofre. Dessa maneira o monitoramento de outros parâmetros é imprescindível para a boa manutenção e conservação do sistema de irrigação.

Para Blum (2003) a presença de sólidos em suspensão pode causar entupimento dos equipamentos de aplicação (aspersores, gotejadores), danos a sistemas de bombeamento, deposição de lodo em excesso em tanques de armazenamento, etc. Podem ser devidos à má operação do sistema de tratamento, à precipitação química após o tratamento ou ao crescimento biológico, e reduzem a eficiência da irrigação.

Neste estudo foi utilizado água residuária sem adição de fertilizantes. $\mathrm{O}$ risco de entupimento dos gotejadores mediante a presença de sólidos foi possivelmente amenizado pela utilização de filtro de discos.

Nas figuras 6 e 7 são apresentados os valores médios mensais de $\mathrm{pH}$ e condutividade elétrica, da água residuária proveniente da ETE, no período de maio a outubro de 2011. 


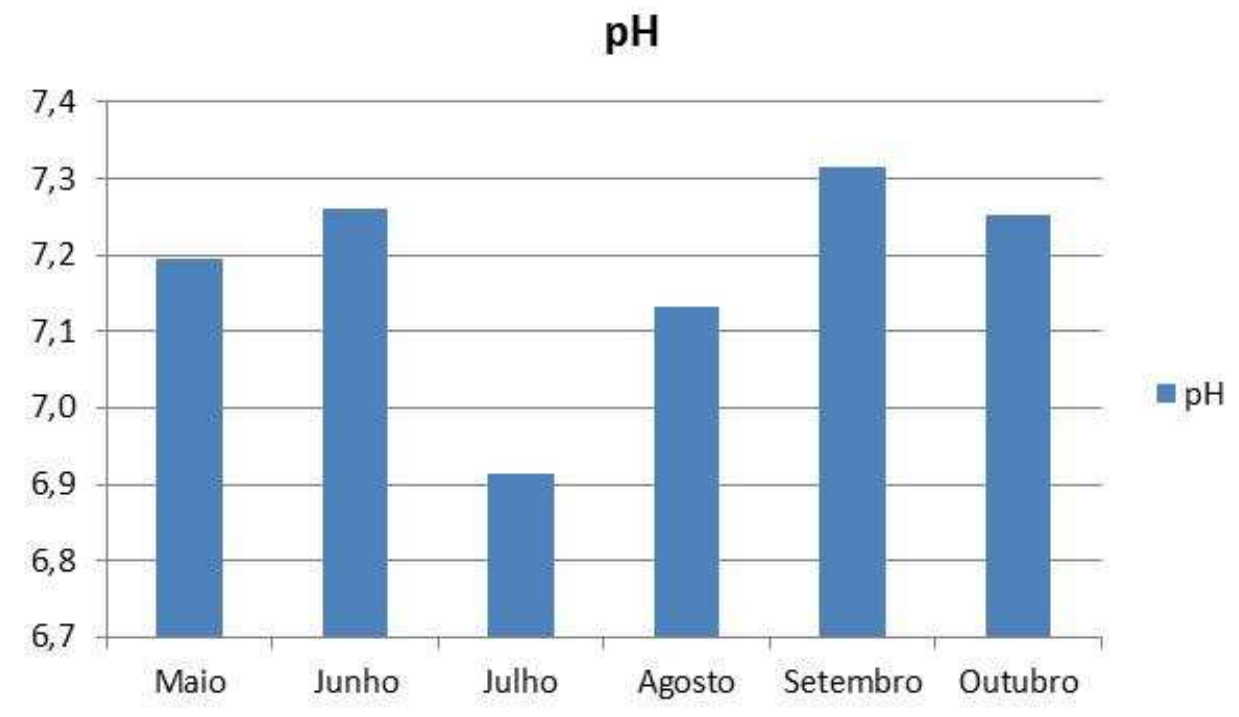

Figura 6. Valores médios mensais de $\mathrm{pH}$.

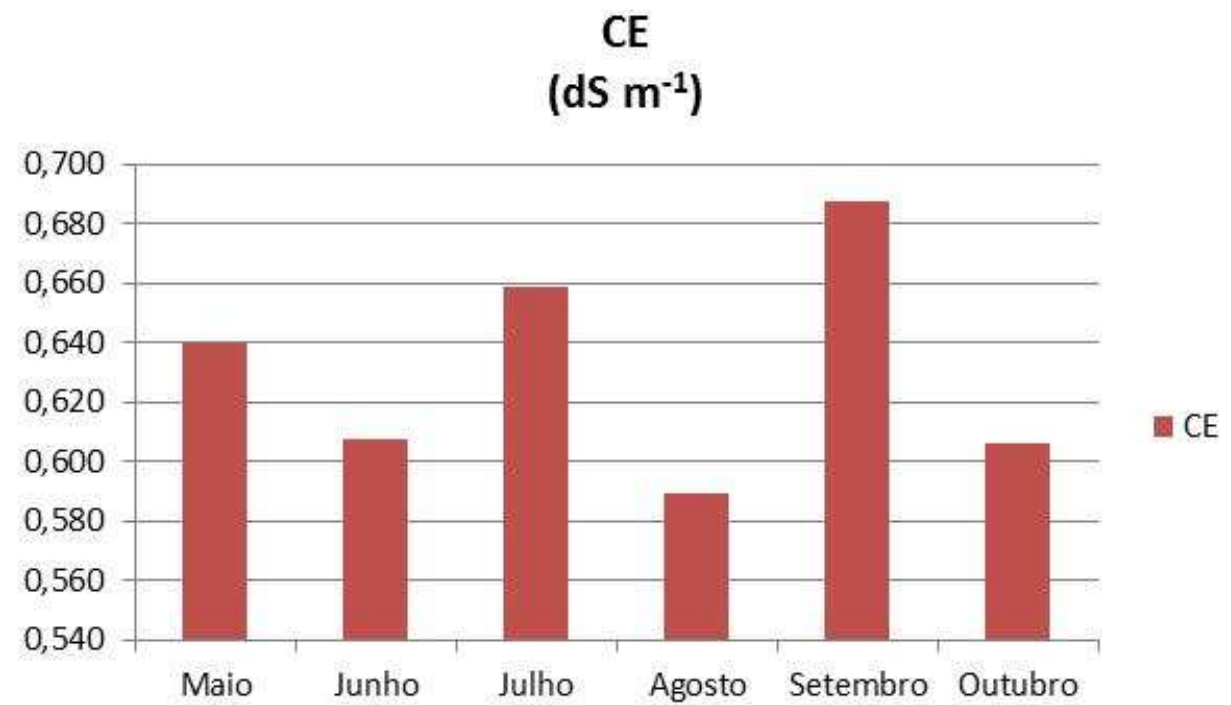

Figura 7. Valores médios mensais de condutividade elétrica.

$\mathrm{O}$ pH de uma água residual permite verificar qual o seu caráter (ácido, neutro ou alcalino). Observa-se que os valores de $\mathrm{pH}$ mantiveram-se praticamente constantes ao longo dos meses, variando de 6,9 a 7,3, portanto neutro. Esses valores encontram-se dentro da faixa especificada ( $\mathrm{pH}$ entre 5 e 9) pela resolução Conama $\mathrm{n}^{\mathrm{o}} .357$ (BRASIL, 2005) que dispõe entre outros sobre as condições e padrões de lançamento de efluentes.

$\mathrm{O}$ mesmo ocorreu com a condutividade elétrica que variou de 0,59 a $0,69 \mathrm{dS} \mathrm{m}^{-1}$. Sabe-se que todo e qualquer sistema de irrigação tem por objetivo suprir a demanda de água pela cultura nos seus diversos estágios de desenvolvimento. Portanto é desejável que o sistema de irrigação seja adequado, e para que este trabalhe de maneira satisfatória, é necessário monitorar a qualidade da água de irrigação para que esta não comprometa o desempenho do sistema, e consequentemente não afete de forma negativa o desenvolvimento da cultura. 
Assim, Gilbert e Ford (1986) citados por Mantovani et al. (2009), propuseram uma classificação da qualidade da água em relação ao potencial de entupimento dos gotejadores, onde o $\mathrm{pH}$ deveria ser menor que 7,0 para um risco baixo, 7,0 a 8,0 risco moderado e maior que 8,0 risco severo (Tabela 3). De uma maneira geral, a água residuária utilizada neste estudo possui risco moderado de entupimento dos gotejadores, visto que para todos os meses os valores permaneceram em torno de 7,0. Vale lembrar que outros parâmetros devem ser observados quanto ao risco de entupimento.

No que se refere à condutividade elétrica $(\mathrm{CE})$, neste estudo não foram observados valores superiores a $0,7 \mathrm{dS} \mathrm{m}^{-1}$, podendo esta água ser classificada com salinidade média (CE entre 0,25 e $0,75 \mathrm{dS} \mathrm{m}^{-1}$, a $25^{\circ} \mathrm{C}$ ) de acordo com a classificação proposta pelo Laboratório de Salinidade dos Estados Unidos (Salasier et al., 2006). Segundo o mesmo autor a principal consequência do aumento da concentração total de sais solúveis de um solo é a redução do potencial osmótico, o que prejudica as plantas, em razão do decréscimo da disponibilidade de água daquele solo. Entretanto não foi observado efeito adverso na cultura do trigo. Sandri et al. (2006) trabalharam com alface irrigada com água residuária aplicada por sistema de irrigação. Na caracterização da água residuária encontraram valores de $\mathrm{pH}$ variando de 7,2 a 7,4 e CE variando de 0,52 a $0,63 \mathrm{dS} \mathrm{m}^{-1}$, valores semelhantes aos determinados neste estudo. Os autores não encontraram efeitos adversos na cultura estudada.

\section{CONCLUSÕES}

- Não foi observado teores de Fe e Mn que comprometessem o sistema de irrigação, ou seja, que apresentasse alto potencial de risco de obstrução de tubulações e emissores (gotejamento);

- A água residuária apresentou caráter neutro, portanto, sem maiores comprometimentos para o sistema de irrigação;

- Não foram constatados valores elevados de condutividade elétrica indicando que essa água pode ser usada no solo, sempre que houver grau elevado de lixiviação, sem maior comprometimento das culturas.

\section{REFERENCIAS BIBLIOGRÁFICAS}

ALMEIDA, O. A. Qualidade da Água de Irrigação.1 ed. Cruz das Almas: Embrapa Mandioca e Fruticultura, 2010. 227 p.

BLUM, J. R. C. Critérios e padrões de qualidade da água. In: MANCUSO, P.C.S.; SANTOS, H. F. Reúso de água. São Paulo: Manole, 2003. p.125-174.

BRASIL. Resolução CONAMA. Conselho Nacional do Meio Ambiente n ${ }^{\circ} .357$ de 17 de março de 2005. Diário Oficial da República Federativa do Brasil, Brasília, DF, 2005. 23 p.

BREGA FILHO, D., MANCUSO, P. C. S. Conceito de reuso de água. In: Reuso de água; Capítulo 2. Eds. P. C. Sanches Mancuso \& H. Felício dos Santos. Universidade de São Paulo - Faculdade de Saúde Pública, Associação Brasileira de Engenharia Sanitária e Ambiental ABES. São Paulo, 2002. 
CAOVILLA, F. A.; SAMPAIO, S. C.; PEREIRA, J. O.; VILAS BOAS, M. A.; GOMES, B. M.; FIGUEIRÊDO, A. C. Lixiviação de nutrientes provenientes de águas residuárias em colunas de solo cultivados com soja. Revista Brasileira de Engenharia Agrícola e Ambiental, Campina Grande, v.9, p.283-287, 2005.

HERNANDEZ, F.B.T.; SILVA, C. R.; SASSAKI, N.; BRAGA, R. S. Qualidade de água em um sistema irrigado no noroeste paulista. In: CONGRESSO BRASILEIRO DE

ENGENHARIA AGRÍCOLA, 30, 2001, Foz de Iguaçu. Anais do XXX Congresso Brasileiro de Engenharia Agrícola, Jaboticabal: Sociedade Brasileira de Engenharia Agrícola, 2001. 1CD-ROM.

KIRKHAM, M.B. Problems of using wastewater on vegetable crops. HortScience, Alexandria, .21, n.1, p.24-7, 1986.

MALAVOLTA, E.; VITTI, G. C.; OLIVEIRA, S. A. Avaliação do estado nutricional das plantas: princípios e aplicações. Piracicaba: POTAFOS, 1997.319p.

MANTOVANI, E. C.; BERNARDO, S.; PALARETTI, L. F. Irrigação: princípios e métodos. 3 ed. Viçosa: Ed. UFV, 2009. 355p.

MORAIS, E.; MAIA, C.; OLIVEIRA, M. Qualidade da água para irrigação em amostras analíticas do banco de dados do Departamento de Solos e Geologia da Escola Superior de Agricultura de Mossoró. Caatinga, Mossoró, v.11, n.1/2, p.75-83, 1998.

SANDRI, D.; MATSURA, E. E.; TESTEZLAF, R. Teores de nutrientes na alface irrigada com água residuária aplicada por sistemas de irrigação. Engenharia Agrícola, Jaboticabal, v.26, n.1, p.45-57, 2006.

SILVA, P. J.; HERNANDEZ, F., B. T.; BARBOZA, G. C.; FRANCO, R. A. M. Avaliação química da água do Córrego do Boi para fins de irrigação. Unesp, Faculdade de Ilha Solteira. Disponível em: http://www.agr.feis.unesp.br/pdf/boi quimica_cic2009.pdf. Acesso em: 27 jan. 2012.

SMANHOTTO, A. Aplicação de água residuária tratada de suinocultura em solo cultivado com soja. 2008. 121f. Tese (Doutorado em Agronomia - Irrigação e Drenagem). Universidade Estadual Paulista, Faculdade de Ciências Agronômicas, Botucatu, SP.

TRANI, P.E.; CARRIJO, O.A. Fertirrigação em hortaliças. Campinas: Instituto Agronômico, 2004. 58 p. (Boletim Técnico IAC, 196).

TRANI, P.E.; RAIJ, B. van. Hortaliças. Boletim Técnico do Instituto Agronômico, Campinas, n. 100, p.30-6, 1997. 